\title{
Sinonasal Adenocarcinoma
}

National Cancer Institute

\section{Source}

National Cancer Institute. Sinonasal Adenocarcinoma. NCI Thesaurus. Code C160976.

Adenocarcinomas that arises from the sinonasal tract. This category includes salivarytype and non-salivary type adenocarcinomas. The latter includes intestinal-type and nonintestinal-type adenocarcinomas. 